\title{
TECENDO EDUCAÇÃO AMBIENTAL E ESTUDOS CULTURAIS
}

\author{
Leandro Belinaso Guimarães ${ }^{1}$, Janice Zanco, \\ Gabriele Nigra Salgado e Sara Melo ${ }^{2}$
}

Resumo: O artigo apresenta o Grupo Tecendo - Educação Ambiental e Estudos Culturais, da Universidade Federal de Santa Catarina (UFSC). Trata-se de um grupo de pesquisa, atualmente integrado ao Núcleo de Infância, Comunicação, Cultura e Arte (NICA), da UFSC, cujos trabalhos articulam educação ambiental e estudos culturais a partir de perspectivas pós-estruturalistas. Iniciamos o ensaio nos valendo de textualidades artísticas para marcar brevemente alguns entendimentos teóricos e práticos que temos operado em nossas pesquisas, principalmente quando usamos noções como cotidiano e lugar. Em seguida, apresentamos o histórico do nosso grupo, que completa dez anos de existência neste ano de 2011. Por fim, o ensaio é encerrado com um resumo das três primeiras dissertações de mestrado desenvolvidas no grupo.

Palavras-chave: estudos culturais, dispositivo artístico, pedagogias culturais.

Abstract: This article presents the Weaving Group - Environmental Education and Cultural Studies, of the Federal University of Santa Catarina. It is a research group, currently integrated to the Center of Childhood, Communication, Culture and Arts (NICA), of the UFSC, whose works articulate environmental education and cultural studies based on post-structuralist perspectives. So, we start this essay using artistic writings to mark briefly some theoretical and practical understandings that have operated in our research, especially when we use notions such as daily life and place. Then, we present the history of our group, which completes ten years of existence in 2011. Finally, the essay ends with a summary of the first three theses developed within the group.

Keywords: cultural studies, artistic device, cultural pedagogies.

\footnotetext{
${ }^{1}$ Professor do Programa de Pós-Graduação em Educação da Universidade Federal de Santa Catarina. Contato: lebelinaso@uol.com.br

2 Biólogas. Mestres em Educação pela Universidade Federal de Santa Catarina. Contatos: Janice: janicezanco@hotmail.com; Gabriele: gabrielesalgado@yahoo.com.br; Sara: saradmelo@gmail.com.
} 


\begin{abstract}
Naquela cidade cada um sonhava o segredo. O menino sem nome conheceu a garota sem pernas. Ela não tinha pernas e, mesmo assim, não precisava de ninguém para ir embora. Eles tentaram. A garota sem pernas mostrou o mundo como conhecia. $\mathrm{O}$ menino que não tinha nome, embarcou. Como quem nunca mais quer voltar. (...) Ela nunca lhe deu um nome. Ele nunca lhe trouxe as pernas. O que para um era sina, para o outro era mistério (Ismael Caneppele, 2010 - com pequenas alterações do autor)
\end{abstract}

O trecho acima destacado inicia o belíssimo livro de Ismael Caneppele, intitulado: "Os famosos e os duendes da morte". Livro que serviu de inspiração para o não menos belo filme, de mesmo nome, dirigido por Esmir Filho. A história é escrita em uma narrativa na qual o leitor se vê convidado a completar sentenças e pensamentos e, nesse movimento, ir também escriturando o próprio texto. Interessante pedagogia de um livro-dispositivo, em que a história a ser contada não é, simplesmente, oferecida ao leitor. Ela dança entre as linhas do próprio texto como se estivesse à deriva, necessitando um leitor - em um corpo singular que produz suor, sentimentos e lágrimas. Um leitor é ativado a encarar as fissuras do texto, seus balanços, suas incompletudes; sem resolvê-las, pois o que mais interessa é esse estar móvel no movimento oferecido pelo texto, em composição na abertura que ele oferece, em experiência. $O$ filme, com suas imagens silenciosas, também convida o espectador para se imiscuir com seus pensamentos no tecido de uma história contra a qual parece, a meu ver, não haver outra saída: há que se digladiar consigo mesmo tecendo a questão: o que estamos fazendo das (com as) nossas vidas?

Trata-se de alguns dias na vida de um adolescente, que tece sua existência em um ambiente rural, recôndito, interiorano, de uma comunidade de descendência alemã no Rio Grande do Sul, Brasil. A Internet é sua porta para o mundo. A personagem da história lembra-me a provocação instaurada por Mia Couto (2005) ao escrever a respeito de como vivem jovens moçambicanos na atualidade: eles "estão mais à vontade diante de um videoclipe de Michael Jackson do que no quintal de um camponês moçambicano"(p. 09). O desejo maior do adolescente, protagonista do filme-livro, é escapar. Entretanto, um embate entre o abandono da segurança do lugar (um deixar algo para trás, um desgrudar-se de si) e a instabilidade, a deriva do partir (um deixar-se levar, um grudar-se ao mundo; quiçá pela tela do computador) é o que vai tecendo seus dias, seus silêncios, seus gritos. A saída, para esse jovem, passa longe da resolução mais evidente e trágica para alguns "daquele lugar": um jogar-se da ponte. Interessante indagação posta por essa personagem, sobretudo para aquela educação ambiental habituada a tentar cravar coletivos humanos em pedaços de territórios e de identidades locais.

"Estar perto não é físico". Essa é uma frase muito presente no filme, que está sutilmente posta no livro. Frase potente. Ela joga o lugar, o espaço do vivido pela janela que se abre ao horizonte (e que muitas vezes penetra inúmeras 
telas do presente: do computador, do celular, da televisão). Interessante tessitura do cotidiano. Esse já não é mais somente o que se apresenta sob os nossos pés, nos sujando de terra, de chão, mas está também em tudo aquilo que toca (muitas vezes sem encostar) o corpo, produz sentidos, sensações. O cotidiano está também, e cada vez mais, na literatura, na televisão, no cinema, na Internet, na música. O lugar é produzido pelo livro e pelo filme como se fosse um inusitado evento (MASSEY, 2008), passível de outras e muitas linhas, algumas advindas de relações tão distantes como as vezes pode parecer as que compõem o quarto que dormimos.

O verdadeiro leitor compreende que os livros são um mundo em si mesmos - e que esse mundo é mais rico e mais interessante do que qualquer outro em que já tenhamos estado (Paul Auster, 2011, p. 392).

Um coletivo de estudantes de Ciências Biológicas da Universidade Federal de Santa Catarina, denominado GEABio (Grupo de Educação e Estudos Ambientais do Centro de Ciências Biológicas) construíram uma inusitada e demasiada interessante intervenção pelos corredores de um dos prédios em que mais circulam na Universidade. Chamaram a intervenção de "Meu MIP, minha casa"3. Trata-se do Departamento de Microbiologia, Imunologia e Parasitologia (MIP) do Centro de Ciências Biológicas da Universidade. Inúmeras imagens foram produzidas a partir da intervenção mostrando os estudantes algumas vezes vestidos de pijama, outras apenas com toalhas de banho, outras em trajes confortáveis como se estivessem "em casa". Eles aparecem dormindo pelos corredores do MIP, acordando, estendendo roupas, fazendo a barba, comendo, estudando, usando o vaso sanitário, se amassando em um elevador (duas meninas em sensuais beijos). A intervenção chama a atenção (instaura uma pergunta) para os usos que eles mesmos tecem cotidianamente com (por entre) os espaços internos da Universidade. Ocupam-se de um lugar por vezes demasiadamente frio, distante, contudo, ao mesmo tempo, aparentemente próximo e perguntam-se sobre como transformá-lo em habitável ao menos por um tempo - este em que um lugar qualquer parece avolumar seus corpos. Os estudantes-artistas parecem tecer sutilmente (e, ao mesmo tempo, de forma contundente) uma questão sobre como um lugar pode vir a expressar os desejos sentidos pelos seus corpos juvenis. Para estes estudantes a resposta parece não estar no próprio lugar, mas nos infinitos elementos de suas vidas que, gritam eles, são necessários para colorir corredores e espaços de uma por vezes fria Universidade. Mais uma vez o desejo é fazer com que um lugar possa deixar-se

\footnotetext{
3 Para outras informações sobre o trabalho acessar: http://www.youtube.com/watch?v= $\mathrm{cpFksiuxljA}$
} 
um pouco dele mesmo e tecer-se também de outros modos, mais conectados aos que ali transitam, gravitam, fogem, permanecem, vivem, sobrevivem.

A nossa única saída é continuar o difícil e longo caminho de conquistar um lugar digno... (...). E esse lugar só pode resultar da nossa própria criação (Mia Couto, 2005, p. 22)

Durante um bom tempo, diria no decorrer de toda a primeira metade dos anos 2000, estivemos em nosso Grupo muito interessados em "compreender como temáticas ligadas ao meio ambiente estavam sendo produzidas através de diferentes grupos humanos e artefatos culturais" (GUIMARÃES, 2007a, p. 243). Um dos nossos interesses era, sem dúvida, fazer com que os sujeitos pudessem atrelar-se com mais densidade aos lugares em que vivem. Trabalhamos, em muitos estudos, com lugares nos quais havia algo de "natureza", ou seja, de territorialidades com certas doses de preservação da biodiversidade. Estávamos mesmo que utilizando referenciais advindos dos estudos culturais que nos faziam questionar o tempo todo o que praticávamos - imiscuídos em uma educação ambiental através da qual queríamos preservar não apenas os ambientes tidos como mais "naturais", mas conservar, resgatar, manter (seja o verbo que quisermos escrever) coletivos humanos com certas doses de "tradição". Esta última, tomada por nós como própria a um lugar e a um coletivo humano. Tinhamos dificuldade de ver coletivos humanos (e de não-humanos) como estando em processos de hibridação, tal como aprendemos com Néstor Garcia Canclini (2000), nos quais elementos díspares se interpenetram, produzindo, em relações assimétricas de saber-poder, uma atualização constante desses próprios coletivos.

Colocamos hoje em dia esse ideário da "conservação" em questão, e são os próprios estudos culturais, sobretudo advindos da America Latina, que nos permitiram iniciar esse deslocamento. Tomar a noção de lugar como um evento (não como algo já dado, concreto, geográfico); pensar os processos culturais como em movimento de hibridação (e não como influenciados por algo que desvirtua um presumível estado de pureza, como muitas vezes os artefatos provenientes das mídias são vistos); atentar para as clivagens, ou seja, as assimetrias nas relações de poder-saber; importar-se com os pensamentos e as vozes dos anônimos com os quais trabalhamos; desejar estar praticando educação ambiental no espaçamento urbano; querer olhar com atenção para as imagens que circulam entre nós; e, por fim, pensar uma pedagogia que possa disparar a criação e potencializar a vida; tudo isso é o que mais nos tem ocupado no momento em nosso Grupo. Para esse esforço tem sido importante inúmeros parceiros, espalhados por esse país continental que é o Brasil, que nos inspiram com seus escritos e amizades por entre as linhas de (de)composição do campo 
fluido e contestado da educação ambiental. São eles (com o risco de esquecer algum): Maria Lúcia Wortmann, Valdo Barcelos, Marcos Reigota, Shaula Sampaio, Lucia Guido, Antonio Carlos Amorim, Ana Godoy, Ana Maria Preve, Paula Henning, Marco Barzano.

$\mathrm{O}$ que distingue uma cultura local de outras quaisquer não são mais sentimentos de clausura, afastamento ou origem, mas as formas específicas pelas quais uma comunidade se posiciona nesse contexto de interconexão e estabelece relações com o outro (Moacir do Anjos, 2005, p. 14).

Passo, agora, após marcar breve e sutilmente, nossas alianças teóricas e práticas, a descrever brevemente o histórico do nosso Grupo, que completa uma década de existência justamente neste ano de 2011. Ele surgiu em agosto de 2001, sendo criado por iniciativa de alguns estudantes de biologia da UFSC, que viam necessidade de agrupar pessoas (alunos e professores) com interesses comuns no que tange ao desenvolvimento de projetos de pesquisa e de extensão universitárias, a respeito, sobretudo, da educação ambiental.

No decorrer dos anos de 2001 e 2002 foram desenvolvidos, no TECENDO (inicialmente chamado de Grupo de Estudos em Educação e Meio Ambiente), seis Trabalhos de Conclusão de Curso (TCC) e a organização de um Curso de Extensão sobre educação ambiental para professores da escola da comunidade pesqueira do Pântano do Sul, em Florianópolis/SC. Além disso, foram realizados inúmeros encontros para discutir textos e projetos de pesquisa, sendo que em alguns momentos houve a participação de diferentes professores para discutir temas específicos.

Nestes anos iniciais, acabei assumindo sua coordenação, sendo que um conjunto de docentes da UFSC também participou de atividades do Grupo: Vera Lícia Vaz de Arruda, Paula Brügger, Natália Hanazaki e Suzani Cassiani,. Alguns dos acadêmicos da UFSC (hoje biólogos) que estiveram mais solidamente vinculados ao Grupo naqueles anos iniciais foram: Rodrigo dos Santos, Ricardo Serafim, Janice Zanco, Rafael Illenseer, Mariana Mascarenhas, Mariana Gama Semeghini e Eduardo Hermes Silva.

Nos anos de 2003 e 2004, o Grupo esteve sob a coordenação das professoras Vera Lícia, Natália e Suzani, que seguiram com encontros para estudos das temáticas pertinentes ao mesmo e com a condução de orientações de pesquisas em educação ambiental (um dos focos centrais do TECENDO), que culminaram em Trabalhos de Conclusão de Curso. Nesta fase eu iniciava meu doutorado e, portanto, afastava-me paulatinamente do Grupo. 
O TECENDO publicou um livro em 2003, pelo Núcleo de Publicações (NUP) do Centro de Educação da UFSC, intitulado: "Tecendo subjetividades em educação e meio ambiente", obra que reúne um conjunto de artigos de pesquisas desenvolvidas por seus integrantes (sobretudo estudantes) nessa sua primeira etapa de trabalhos (anos 2001 e 2002). O Grupo também estará lançando uma publicação, decorrente do trabalho desenvolvido pelos seus integrantes nos anos 2003 e 2004, que será publicada pela Editora da UFSC (provavelmente em 2011), sob o título: "Tecendo reflexões em educação e meio ambiente". Essa obra foi organizada pelas professoras Natália Hanazaki e Vera Lícia Vaz de Arruda. Em 2010, lançamos o livro "Tecendo educação ambiental na arena cultural", que reúne, sobretudo, alguns artigos de TCC desenvolvidos no Grupo em sua fase mais recente, além de incluir textos de pesquisadores que são nossos parceiros.

Nos anos de 2005 e 2006, o Grupo fez uma pausa em suas atividades, retomando-as, paulatinamente, em 2007. A partir de fevereiro de 2008, o Grupo se consolida novamente sob a minha coordenação (já com meu retorno do doutorado), passando a chamar-se "TECENDO - Educação Ambiental e Estudos Culturais"4. Nesse atual momento estiveram mais fortemente articulados ao Grupo: Julia Locatelli, Laise Orsi Becker, Franciele Favero, Janice Zanco, Sara Melo, Aline Krelling, Gabriele Salgado, entre outros que gravitaram pelo TECENDO durante a confecção das suas monografias ou desenvolvendo um estágio de pesquisa.

Para registrar o atual momento do Grupo, passo a apresentar as três dissertações de mestrado que já estão sendo finalizadas no TECENDO (duas delas têm suas defesas agendadas para julho de 2011), pois desde 2008 sou pesquisador do Programa de Pós-Graduação em Educação (PPGE) da UFSC, na Linha Educação e Comunicação e pesquisador do NICA - Núcleo de Infância, Comunicação, Cultura e Arte. Deixo, nesse texto, de marcar a pesquisa que desenvolvo atualmente sobre a atuação de um "dispositivo da sustentabilidade" no tempo presente. Haverá oportunidade em outros artigos, para que possa expor algo sobre ela, bem como sobre o que temos chamado recentemente em nosso Grupo de uma "educação ambiental como dispositivo artístico". É a noção de "dispositivo" (a partir do pensamento de Michel Foucault, mas atualizada pelos estudos de cinema e pelos estudos sobre as artes contemporâneas) que mais temos estudado ultimamente e que nos tem inspirado a montagem de nossas pesquisas que, muitas vezes, incluem intervenções sociais. Passo, então, já encaminhando para a finalização desse artigo, a apresentar resumidamente as três primeiras dissertações tecidas no Grupo. Os textos que seguem foram escritos pelas próprias pesquisadoras, cujos nomes seguem ao subtítulo da seção.

\footnotetext{
${ }^{4}$ Para saber mais acesse: $\underline{\text { ww. grupotecendo.com.br }}$
} 


\section{Foto(dispositivo): Educação Ambiental entre as imagens do Sertão do Peri produzidas pelas pessoas que o habitam, por Gabriele Nigra Salgado}

Este estudo advém de minhas inquietações acerca do "silenciamento" da população que habita uma determinada região do Parque Municipal da Lagoa do Peri, em Florianópolis/SC, conhecida como Sertão do Peri. Esta região foi categorizada pelo plano diretor que orienta a implantação desta Unidade de Conservação como sendo uma Zona de Paisagem Cultural, uma vez que seus habitantes são descendentes de imigrantes açorianos e, portanto, mantêm práticas de subsistência - principalmente agrícolas - tidas como "tradicionais" desta cultura, como a produção de cachaça e farinha de mandioca a partir de engenhos movidos a tração animal e, mais recentemente, por energia elétrica. Muitas imagens marcam esta região com discursos que considero mais legitimados que os de seus habitantes devido à relação de poder que está em jogo neste embate que envolve populações vivendo em áreas de preservação permanente. Que imagens seriam produzidas pelos habitantes do Sertão do Peri caso lhes fossem sugerido fotografar o ambiente em que vivem e as coisas que nele acontecem? Movida por este questionamento inicial e com base em autores tidos como de inspiração teórica pós-moderna me propus a investigar como este ambiente do Parque Municipal da Lagoa do Peri é narrado por esta população que habita o sertão: Que outros sertões seriam possíveis de serem enunciados por meio deste convite a fotografar o lugar em que vivem? Como os moradores e as moradoras do Sertão do Peri, constituem relações com os ambientes em que vivem, os quais são protegidos por determinações legais? Sobretudo, é minha intenção investigar como os modos de ver um lugar habitado atravessam os olhos de personagens que preenchem com suas existências um lugar específico. Deste modo discuti os fios que estão em jogo nas tramas que vão compondo e/ou recompondo os diferentes "lugares" de um mesmo Parque que é percebido a partir das particularidades das relações estabelecidas com este ambiente e das lentes culturais e históricas de cada sujeito.

Interessa-me também, pensar a educação ambiental sob a concepção pós-moderna de dissolução das essências para emergir a diferença. Não pretendo abordar os moradores do Sertão com discursos que enunciem aquilo que se deve ou não ser feito e pensado para adequar comportamentos a um modo considerado ético de se habitar uma área de preservação. Uma educação ambiental pensada sob este outro enfoque tem a pretensão de promover a desconstrução das representações para promover outros modos de ver um lugar preenchido com as existências de diferentes sujeitos. Isto porque, partimos da constatação de que algumas narrativas são tão recorrentes que se tornam "naturalizadas" (vistos como já dados no mundo) e, assim a pesquisa busca suscitar dúvidas sobre tais construções, mostrando o caráter social, cultural e histórico de tais invenções (GUIMARÃES, 2007b).

Sendo assim, como pensar uma educação ambiental no Parque que permita indagações sobre as relações socioambientais desses sujeitos? Neste trabalho, o ato de fotografar é pensado como um dispositivo artístico potente 
para a educação ambiental, capaz de promover a criação de outros enunciados, conduzindo outra relação com a fotografia, sendo esta uma estrutura autônoma e imponente pela força de sua auto-referência (XAVIER, 2008).

\section{O ambiente cantado e contado por brincantes de coco de roda da Paraíba, por Sara Melo.}

A maneira como cada um de nós se relaciona com o ambiente é fortemente constituída pela cultura em que estamos inseridos. Esta cultura permeia não só como interpretamos o ambiente, como nossa forma de pensar e os modos como nos movimentamos no mundo. Assim, como educamos e somos educados, nossas atitudes políticas e formas de agir com relação ao ambiente estão intimamente relacionados à cultura.

Escolhi a música como um possível meio de se ouvir as vozes dos sujeitos, permitindo que os brincantes de coco de roda narrem e expressem suas impressões do ambiente. Através de um elemento que já faz parte do seu universo cultural e cotidiano, busquei um caminho de acesso ao imaginário popular, o qual está fundamentado muitas vezes na vivência dos sujeitos com o ambiente, abordando hábitos de animais, plantas e interações comportamentais, atividades profissionais e cotidianas (pescadores, canoeiros, catadores de caranguejo, entre outras).

Meu trabalho investigou como o ambiente é representado através das cantigas do coco de roda e algumas cirandas da Paraíba. Tem inspiração dos Estudos Culturais e baseia-se também em conceitos como pedagogia cultural, buscando entender o que as canções e narrativas em questão nos ensinam sobre o ambiente.

O trabalho de campo foi realizado durante os meses de janeiro e fevereiro de 2010, no Estado da Paraíba. Foram entrevistados 24 brincantes e/ ou mestres de coco de roda em 8 localidades, algumas nos arredores de João Pessoa, comunidades quilombolas e indígenas. $O$ que unia essas localidades diversas era a presença de mestres e brincantes de coco de roda e ciranda. Foram utilizadas metodologias variadas como registros em audiovisual, história oral e entrevistas semi-estruturadas. Era pedido aos brincantes que cantassem canções relacionadas ao ambiente em que vivem e contassem histórias que se passaram com eles ou com algum conhecido nesses locais. Foram cantados uma variedade grande de cocos e ciranda e contadas histórias sobre seres que habitam as matas, mangues, mares e rios, como Comadre Fulozinha, Pai do Mangue, Mãe D’ Água entre outros. 


\section{Dona Generosa e as crianças disparam... outros modos de ver a Lagoa do Peri, por Janice Zanco.}

Uma pesquisa que encontra crianças. Crianças entre 9 e 13 anos de idade, de uma escola municipal do sul da Ilha de Santa Catarina, Brasil. Eu queria entrar em contato com as novas formas de ver e narrar a Lagoa do Peri (Parque Municipal da Lagoa do Peri), sob o ponto de vista dessas crianças da região. Para isso pensei em elaborar práticas pedagógicas. Precisava provocar uma experiência única, algo que mexesse com as crianças, com a professora, com a escola e comigo. Encontrei na brincadeira do faz-de-conta uma maneira de conseguir o que queria, ou seja, provocar novas narrativas e uma experiência imaginativa. Pensando assim, a brincadeira que criei foi: Vamos fazer de conta que existe uma senhora chamada dona Generosa. Ela mandou cartas para as crianças e as convidou para que fizessem uma pesquisa. Quem é dona Generosa? Ela escreve, ela fala, manda recados. Criei uma história, recheada de mistérios e levei as crianças para fazerem uma pesquisa na e sobre a Lagoa do Peri. Elas foram estimuladas a narrar histórias, que tivessem como pano de fundo essa Lagoa, por meio de diferentes formas: ouvindo e contando histórias, desenhando, escrevendo, filmando, fotografando. A misteriosa dona Generosa não foi descoberta. Quem sabe, um dia! Por enquanto, ficam pontos de interrogação em cada cabecinha. Ficam fotos, vídeos, falas, desenhos e escritas sobre o que os pesquisadores e pesquisadoras perceberam, sentiram, viram, duvidaram sobre os seres fantásticos da Lagoa do Peri. Eu pensava em focar nas narrativas das crianças, porém percebi que o processo em si é que merecia destaque e reflexão. No momento em que me deparei com todo o material produzido pelos alunos e alunas as minhas perguntas já não faziam mais sentido. Tinha a certeza de que não queria nem conseguiria categorizar nem os escritos, nem os desenhos, nem as imagens, talvez por um receio de simplificá-los. Pensando em tudo isso, na inventividade do modo de construção da pesquisa, e no que aconteceu durante os encontros com os alunos e as alunas, fiquei então muito mais preocupada em discutir como foi esse nosso processo. Foi nesse deslizamento que percebi a principal busca da pesquisa: como construir uma trilha na qual os silêncios possam estar presentes, visíveis e enunciados?

\section{Referências}

ANJOS, Moacir dos. Local/global: arte em trânsito. Rio de Janeiro: Jorge Zahar, 2005.

AUSTER, Paul. Entrevista. In: As entrevistas da Paris Review (volume 1). São Paulo: Companhia das Letras, 2011.

CANEPPELE, Ismael. Os famosos e os duendes da morte. São Paulo: Iluminuras, 2010.

CANCLINI, Néstor Garcia. Notícias recientes sobre la hibridación. In: HOLLANDA, Heloísa Buarque; RESENDE, Beatriz. Artelatina: cultura, globalização e identidades cosmopolitas. Rio de Janeiro: Aeroplano Editora e Museu de Arte Moderna do Rio de Janeiro, 2000. 
COUTO, Mia. Pensamentos: textos de opinião. Lisboa: Editorial Caminho, 2005.

GUIMARÃES, Leandro Belinaso. Pesquisas em educação ambiental: olhares atentos à cultura. In: WORTMANN, Maria Lúcia, SANTOS, Luís Henrique, RIPOLL, Daniela, SOUZA, Nádia, KINDEL, Eunice (Orgs.). Ensaios em estudos culturais, educação e ciência. Porto Alegre: UFRGS, 2007a.

- Fulgurações: pelos rastros da educação ambiental. In: Ana Maria Preve; Guilherme Corrêa. (Orgs.). Ambientes da Ecologia: perspectivas em política e educação. Santa Maria: UFSM, 2007b.

GUIMARÃES, Leandro Belinaso, BRUGGER, Paula, SOUZA, Suzani Cassiani, ARRUDA, Vera Licia. (Orgs.). Tecendo subjetividades em educação em meio ambiente. Florianópolis: NUP/CED/UFSC, 2003.

GUIMARÃES, Leandro Belinaso, KRELLING, Aline, BARCELOS, Valdo (Orgs.). Tecendo educação ambiental na arena cultural. Petrópolis: DP\&Alli, 2010.

MASSEY, Doreen. Pelo espaço: uma nova política da espacialidade. Rio de Janeiro: Bertrand Brasil, 2008.

XAVIER, Ismail. Um cinema que "educa" é um cinema que (nos) faz pensar (entrevista). Educação \& Realidade. Porto Alegre, v. 33, n. 1, 2008.

Artigo recebido em 20/08/2010 - - aprovado em 17/12/2010 